\title{
Cynaropicrin Potentiates the Anti-Tumor Effects of Paclitaxel and 5-Fluorouracil on KYSE30 Human Esophageal Carcinoma
}

\section{Solmaz Nasirzadeh}

Ferdowsi University of Mashhad

Ahmad Reza Bahrami

Ferdowsi University of Mashhad

Seyed Navid Goftari

Ferdowsi University of Mashhad

Abolfazl Shakeri

Mashhad University of Medical Sciences

Mehrdad Iranshahi

Mashhad University of Medical Sciences

Maryam M. Matin ( $\square$ Matin@um.ac.ir)

Ferdowsi University of Mashhad https://orcid.org/0000-0002-7949-7712

\section{Research Article}

Keywords: Esophageal cancer, Combination therapy, Cynaropicrin, Synergistic effects.

Posted Date: August 19th, 2021

DOl: https://doi.org/10.21203/rs.3.rs-816266/v1

License: (9) (i) This work is licensed under a Creative Commons Attribution 4.0 International License. Read Full License 
Cynaropicrin potentiates the anti-tumor effects of paclitaxel and 5-fluorouracil on KYSE30 human esophageal carcinoma

Solmaz Nasirzadeh ${ }^{1}$, Ahmad Reza Bahrami ${ }^{1,2}$, Seyed Navid Goftari ${ }^{1}$, Abolfazl Shakeri ${ }^{3}$, Mehrdad Iranshahi ${ }^{3,4}$, Maryam M. Matin ${ }^{1,5^{*}}$

1. Department of Biology, Faculty of Science, Ferdowsi University of Mashhad, Mashhad, Iran

2. Industrial Biotechnology Research Group, Institute of Biotechnology, Ferdowsi University of Mashhad, Mashhad, Iran

3. Department of Pharmacognosy, Faculty of Pharmacy, Mashhad University of Medical Sciences, Mashhad, Iran

4. Biotechnology Research Center, School of Pharmacy, Mashhad University of Medical Sciences, Mashhad, Iran

5. Novel Diagnostics and Therapeutics Research Group, Institute of Biotechnology, Ferdowsi University of Mashhad, Mashhad, Iran

E-mail: matin@um.ac.ir

Tel: $+98-51-38805514$

Fax: +98-51-38796416 


\section{Abstract}

2 Natural products or their use in combination therapy regimens may reduce side effects of

3 chemotherapy and increase the effectiveness of treatments. The cytotoxic effects of 4 cynaropicrin, a sesquiterpene lactone isolated from Centaurea behen were evaluated for the

5 first time against esophageal squamous carcinoma cells (KYSE30). The synergistic effects of 6 cynaropicrin with paclitaxel and 5-fluorouracil (5-Fu), conventional chemotherapeutic drugs

7 used for esophageal cancer treatment, were also investigated. MTT results indicated that the $850 \%$ inhibitory concentration ( $\mathrm{IC}_{50}$ ) values of cynaropicrin on KYSE30 cells after 24, 48 and $972 \mathrm{~h}$ were 72,43 and $28 \mu \mathrm{M}$, respectively, which were significantly different from those on 10 normal HDF cells. It was also determined that cynaropicrin could induce the cell death via apoptosis. Our results indicated that cynaropicrin had synergism with both drugs. The best effects of cynaropicrin in combination with paclitaxel were observed at $48 \mathrm{~h}$, in which dose reduction of paclitaxel reached 3 times in $\mathrm{IC}_{50}$. Combination with 5-fluorouracil, resulted in 15 times dose reduction of 5-Fu in $\mathrm{IC}_{50}$ at $24 \mathrm{~h}$. In conclusion cynaropicrin has selective cytotoxic effects on KYSE30 cells and we suggest its use in combination therapies with paclitaxel and 5-Fu, which would reduce the side effects of these conventional treatments.

Keywords: Esophageal cancer, Combination therapy, Cynaropicrin, Synergistic effects. 
The geographical distribution of esophageal cancer is variable in different parts of the world, reflecting the impact of environmental conditions, lifestyle and genetic factors on development of this disease (Mir et al., 2005; Wang et al., 2020). The incidence of this cancer is usually three to four times higher in men than women (Ferlay et al., 2015; Torre et al., 2015). In 2012, about 400,000 deaths from esophageal cancer and 456,000 new cases of this disease were documented (Ferlay et al., 2013; Ferlay et al., 2015., Liang et al., 2017). Nearly $80 \%$ of new cases occur in less developed regions of the world (Enzinger et al., 2003; Ferlay et al., 2015; Wong et al., 2018). Eastern Asia, eastern and southern Africa have the highest incidence of esophageal cancer and western Africa has the lowest (Torre et al., 2015; Liang et al., 2017; Wong et al., 2018). This type of cancer is divided into two main forms with specific cause and distinct pathological features, including: esophageal squamous cell carcinoma (ESCC) and esophageal adenocarcinoma (EAC) (Jemal et al., 2011; Zhang et al., 2012; Malhotra et al., 2017). In 2012, nearly 90\% of reported cases of esophageal cancer in the world were ESCC (Arnold et al., 2015; Abnet et al., 2018). In a region, often known as "esophageal cancer belt" extending from northern Iran through the Central Asian republics to the north central China, 91\% cases of esophageal cancer are ESCC (Tran et al., 2005; Akbari et al., 2006; Siegel et al., 2015; Komal et al., 2019). ESCC is highly invasive and is usually diagnosed in advanced stages and thus it has a very poor prognosis (Quint et al., 1995; Jemal et al., 2005; Aghcheli et al., 2011; Abnet et al., 2018; Zhang et al., 2020). The survival rate of ESCC in developed countries is 10 to 15\% (Moyana et al., 1996; Wang et al., 2017; Abnet et al., 2018). In advanced stages, that cancer has metastasized to the surrounding tissues such as lymph nodes, chemotherapy or combination of chemotherapy, radiotherapy and surgery are the preferred options for esophageal cancer treatment (Lagergren et al., 2017; Hou et al., 
cause very severe side effects (Qi et al., 2010; Shapiro, 2016; Turcotte et al., 2017). Studies

52

suggest that radiations used for radiotherapy, increase the cancer invasion power, tumor migration and metastasis. In the case of chemotherapy, very high toxicity and low efficacy have caused pessimism to this treatment (Camphausen et al., 2001; Wild-Bode et al., 2001; Jung et al., 2007; Huang et al., 2017). Generally, the complexity of the formation and development of esophageal cancer prevents effective treatment (Qi et al., 2010; Yang et al., 2012; Hu et al., 2016).

During the past decades, use of targeted therapy has evolved greatly, however over the last few years, this strategy has been geared towards combination therapy (Devita et al., 1975; Chesney et al., 2000; Jukema and van der Hoorn, 2004; Weber and Noels, 2011; Gosh et al., 2018), because the traditional use of a single drug for treatment of complex diseases, such as cancer, is usually not effective. Using a combination of drugs, usually reduces their adverse effects (Nowak et al., 2016; Mokhtari et al., 2017). The combination of drugs can lead to additive, synergistic, antagonistic, or suppressive effects, however the best situation is a combination that leads to synergism as it reduces the dosage and drug resistance, increases the efficacy of treatment, and strengthens drug targeting. This type of treatment is considered as a standard method for cancer therapy (Devita et al., 1975; Jia et al., 2009; Zhang et al., 2012; Mokhtari et al., 2017). It can also be stated that the biological effects of compounds in a combined state are much greater than a single compound. The mixture of the compounds has multiple bioactive effects due to having different targets (Devita et al., 1975; Chesney et al., 2000; Jukema and van der Hoorn, 2004; Weber and Noels, 2011; Mokhtari et al., 2017).

Natural products constitute safe, endless, and rich sources of drugs for treatment of various diseases (Rates, 2001; Haefner, 2003; Butler, 2004; Raskin et al., 2004; Cragg et al., 2005; Mishra et al., 2011; Rey-Ladino et al., 2011; Alam et al., 2018). There has been a lot of interest in developing alternative chemotherapy regimens that tend to use natural compounds, 
especially medicinal herbs (Fu et al., 2009; Kaur et al., 2011; Mansoori et al., 2019). From 155 anti-cancer drugs made since 1940, about 50\% were either from natural products or their derivatives (Kinghorn et al., 2009; Ahmad et al., 2016; Newman et al., 2016; Elrayess et al., 2019). This tendency to natural products is mostly due to the mentioned disadvantages of conventional drugs, such as ineffectiveness, side effects and toxicity on normal cells (Fu et al., 2009; Kaur et al., 2011; Mansoori et al., 2019). Furthermore, natural compounds are safe and can lead to development of more effective therapeutic agents (Rates, 2001; Mansoori et al., 2019). Natural secondary metabolites with herbal origin play an important role in cancer chemotherapy (Mehhndiratta et al., 2011; Seca et al., 2018). Sesquiterpene lactones (SLs) are a large and diverse group of natural products found in more than 100 flowering plant families. The highest numbers of SLs have been extracted from the plants belonging to the family Asteraceae (Heinrich et al., 1998), which are rich in bioactive compounds (secondary metabolites) such as polyacetylenes, diterpenes and SLs (Herz, 1977). These compounds have many therapeutic activities including anti-inflammatory, anti-tumor, anti-microbial and anti-viral properties (Baruah et al., 1994; Zhang et al., 2005; Xavier-ravi et al., 2019). SLs have been reported as promising anti-cancer agents with potentials in both chemotherapy and chemoprevention (Akao et al., 2013; Quintana et al., 2018). They exert their properties by inhibiting inflammatory responses, preventing metastasis, and inducing apoptosis (Zhang et al., 2005; Quintana et al., 2018).

Centaurea L. with more than 700 species is one of the largest genera in the family Asteraceae (Bensouiciet al., 2012). Members of this genus are spread all over the world (Forgo et al., 2012). The main and most important compounds identified in this group are SLs (Cardona et al., 1994; Georgiadou et al., 2000). Centaureais well known in folk medicine for its antimicrobial, anti-cancer, anti-diabetic, anti-rheumatic, anti-pyretic, anti-inflammatory, stimulant, tonic, and some other properties (Garbacki et al., 1999; Akkol et al., 2009; Koca et 

al., 2009; Chougule et al., 2012). According to several experiments, SLs are responsible for the therapeutic properties of this genus (Chicca et al., 2011). Centaurea behen is an annual herb belonging to genus Centaurea. It is native to Iran, and is known as an Irano-Turanian plant. In Iran it is known as Bahman Sefid. C. behen also grows in countries such as Iraq, Pakistan, and India as well as North Africa and Europe (Khare, 2004; Mozaffarian, 2012; Mosaddegh et al., 2018). C.behen is used for traditional treatment of a number of diseases, including cystic fibrosis, central nervous system (CNS) disorders, and kidney stone, and is also used for itscardiotonic, sedative, anti-inflammatory,emmenagogue and aphrodisiac properties (Yadava et al., 2006, Mozaffarian, 2012; Mosaddegh et al., 2018). A number of SLs, including arguerin B, grosshemin and cynaropicrin, have been purified from this species (Oksuz et al., 1982). Researchers have proven that cynaropicrin has a wide variety of biological activities including: anti-tumor (Zong et al., 1994; Ha et al., 2003; Muhammad et al., 2003; Cho et al., 2004; Cho et al., 2004b; Choi et al., 2005; Kolli et al., 2012; Salvador et al., 2008; Yang et al., 2008; Butturini et al., 2013; liu et al., 2019), anti-inflammatory (Cho et al., 1998; Cho et al., 2000; Hayat et al., 2019), anti-parasitic (Schinor et al., 2004; Drab et al., 2005; Zimmermann et al., 2012; da Silva et al., 2013; Mokoka et al., 2013), anti-bacterial (Bachelier et al., 2006), anti-photoaging, anti-oxidant (Tanaka et al., 2013; Yamada et al., 2015) and anti-spasmodic, through inhibiting the production of cytokines such as TNF $\alpha$ and suppression of NF- $\kappa \mathrm{B}$. Anti-cancer effects of cynaropicrin on various cancers such as stomach, lung, breast and leukemia have been already reported (Cho et al., 2004b). According to the global burden of disease (GBD) statistics, esophageal cancer is among the six most common cancers that has imposed heavy burdens on Iranian society (Majidi et al., 2017), but despite these reports, little studies have been carried out on this cancer in Iran.In the present study we aimed to: 1) evaluate the cytotoxic and anti-cancer properties of cynaropicrin on ESCC cells for the first time, 2) determine the mechanism of cell death 
induced by cynaropicrin, and 3) investigate its synergistic effects in combination with common drugs used in esophageal cancer chemotherapy, such as paclitaxel and 5fluorouracil, in order to reduce the dose and subsequently, side effects of these medications.

\section{Materials and Methods}

\section{Chemicals}

Roswell Park Memorial Institute (RPMI)- 1640 medium, Dulbecco's modified Eagle's medium (DMEM) and fetal bovine serum (FBS) were purchased from Thermo Fisher Scientific and 3-[4, 5-dimethylthiazol-2-yl]-2, 5-diphenyl-tetrazolium bromide (MTT) was obtained from Sigma Aldrich. Anti-cancer drugs used in this study include: paclitaxel (pac) from Actavis and 5-fluorouracil (5-Fu) from Elewe PHARMA. FITC-Annexin V Apoptosis Detection Kit with propidium iodide (PI) was purchased from BioLegend. Cynaropicrin was extracted and purified from $C$. behen (voucher specimens: No. 12405) in our previous work (Shakeri et al., 2018).

\section{Cell culture}

Human esophageal cancer cell line (KYSE30) (Pasteur Institute, Iran) was cultured in RPMI1640 with $10 \%$ FBS as a supplement, and human dermal fibroblast cell line (HDF) as normal cells (a generous gift from ACECR) were cultured in high glucose DMEM containing 15\% FBS. Both cell lines were cultured at $37^{\circ} \mathrm{C}$ in a humidified atmosphere containing $5 \% \mathrm{CO}_{2}$ (Lim et al., 2000; Pan et al., 2014). 
Cell viability was evaluated by MTT assay. To do so, cells were cultured (9000 cells/well for KYSE30 and 10000 cells/well for HDF) in 96 well plates (Orange Scientific), and treated with various concentrations of cynaropicrin (KYSE30 and HDF cells), pac, 5-Fu, cynaropicrin-pac and cynaropicrin-5-Fu (only KYSE30 cells) for 24, 48 and $72 \mathrm{~h}$. Finally, cells were incubated with $20 \mu \mathrm{l}$ MTT per well and after $4 \mathrm{~h}$ the absorbance of formazan crystals dissolved in dimethyl sulfoxide (DMSO) was measured at $570 \mathrm{~nm}$ by an ELISA plate reader (AWARENESS, USA).

\section{Apoptosis detection}

KYSE30 cells treated with $25 \mu \mathrm{g} / \mathrm{ml}$ cynaropicrin for $15 \mathrm{~h}$ were dually stained with FITCannexin V and PI for detection of apoptotic cells. Following BioLegend's instructions, treated cells were first washed with staining buffer. After harvesting and centrifugation, annexin V binding buffer was added and cells were stained with FITC-annexin V and PI for 15 min (in the dark). Finally, cells were subjected to flow cytometry to analyze the mechanism of cell death induced by cynaropicrin.

Investigating the synergistic effects of cynaropicrin with chemotherapy drugs

KYSE30 cells were treated with cynaropicrin, pac and 5-Fu, separately. Inhibitory concentration $\left(\mathrm{IC}_{50}\right)$ for each agent was evaluated by MTT assay after 24,48 and $72 \mathrm{~h}$.

171 According to median effect method of Chou-Talalay and using $\mathrm{IC}_{50 \mathrm{Cyn}} / \mathrm{IC}_{50}$ drug relationship or inverse, the combination ratio was evaluated for cynaropicrin-pac and cynaropicrin-5Fu in all three time periods. KYSE30 cells were then treated with a combination of cynaropicrinpac and cynaropicrin-5-Fu for $72 \mathrm{~h}$. Synergistic effects of cynaropicrin with any of the used drugs was determined through evaluating the combination index (CI) and dose reduction 
index (DRI) using the Calcu-Syn software (Biosoft, Cambridge, UK). In this regard, CI $<1$ means synergistic effects, $\mathrm{CI}=1$ means additive effects and $\mathrm{CI}>1$ means antagonistic effects (Chou, 2010; Ashton, 2015).

Statistical analyses

Statistical analyses were performed using GraphPad Prism v. 6.07. Significant differences were ascertained by one-way ANOVA and multiple $t$-test. In the case of calculating the synergistic effects, Calcu-Syn software was used.

\section{Results}

Investigating the cytotoxic effects of cynaropicrin on KYSE30 cells

187 MTT assay was used to evaluate the cytotoxicity of cynaropicrin on esophageal cancer cells. To do so, cells were treated with different concentrations of the agent for 24,48 and $72 \mathrm{~h}$. $\mathrm{IC}_{50}$ values were calculated as $25.11,15.39$ and $9.94 \mu \mathrm{g} / \mathrm{ml}$ equal to 72,43 and $28 \mu \mathrm{M}$ for 24 , 48 and $72 \mathrm{~h}$, respectively. Dose-response curves and $\mathrm{IC}_{50}$ values are shown in Fig. 1, indicating that cynaropicrin cytotoxicity on KYSE30 cells is concentration- and timedependent. (Supplementary Graph 1, Comparison: 5 and Supplementary Image: 1, 2 and 3). 
203

204

205

206

207

208

209

210

211

212

213

214

215

216

217

218

219

220

221

222

223

224

225
B

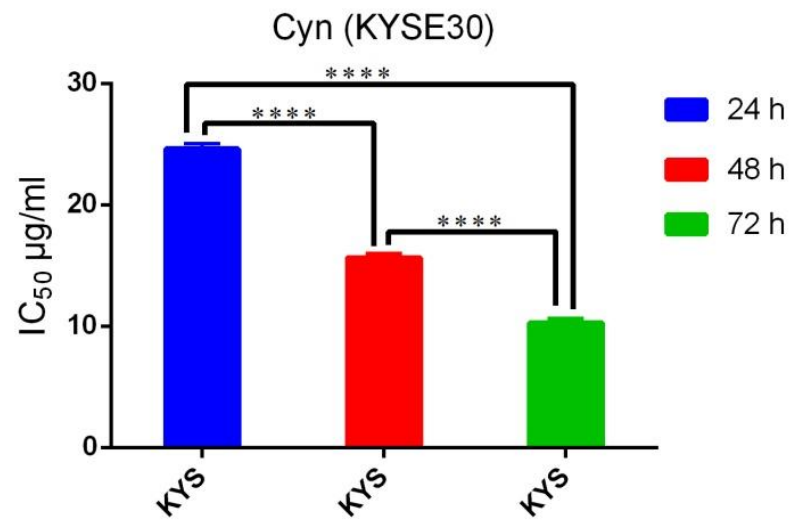

Fig. 1: A) Dose-response curves indicating the cytotoxic effects of cynaropicrin on KYSE30 cells. The graphs show the survival percentage of cells after treatment with different concentrations of cynaropicrin at 24, 48 and $72 \mathrm{~h}$. The data are average of three repeats in each concentration with SEM. B) Comparing the $\mathrm{IC}_{50}$ values of cynaropicrin on KYSE30 cells at 24, 48 and 72 h. Columns are plotted with standard deviation. **** indicates the significance of the differences at the levels of $p<0.0001$.

To evaluate the anti-cancer effects of cynaropicrin, the same assay was performed on HDF, as normal cells. Values of $58.06,46.31$ and $33.40 \mu \mathrm{g} / \mathrm{ml}$ were calculated as $\mathrm{IC}_{50}$ of cynaropicrin at 24, 48 and 72 h, respectively. As indicated in Fig. 2, the results showed that cynaropicrin toxicity on this cell line is also concentration- and time- dependent. (Supplementary Graph 2, Comparison: 6 and Supplementary Image: 4, 5 and 6).

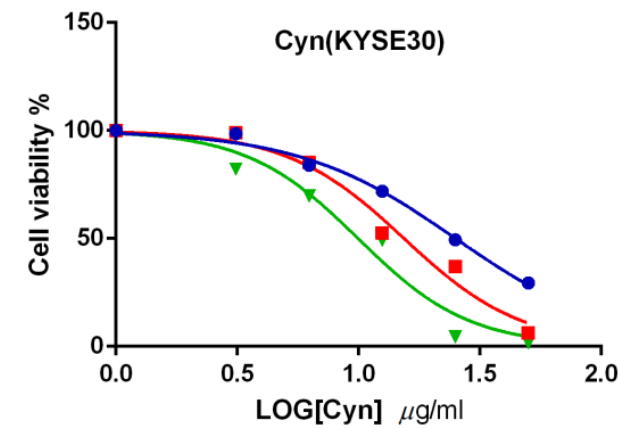

$-48 \mathrm{~h}$
$-72 \mathrm{~h}$ 
233

234

235

236

237

238

239

240

241

242

243

247

248

249

250

251

252

253

254

255

256

257

258

259

260

261

262
B

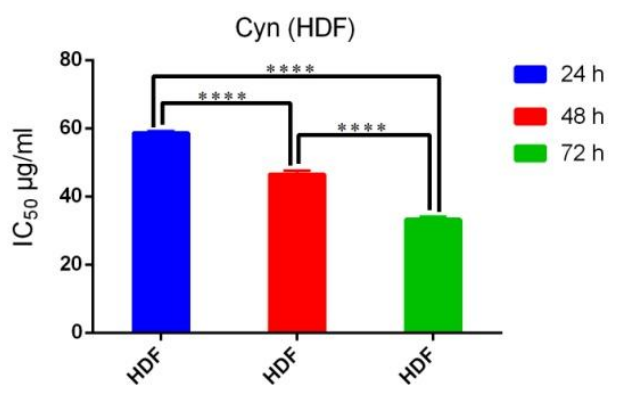

Fig. 2: A) Dose-response curves indicating the effects of cynaropicrin on HDF cells. The graphs show the survival percentage of cells after treatment with different concentrations of cynaropicrin at 24,48 and $72 \mathrm{~h}$. B) Comparing $\mathrm{IC}_{50}$ values of cynaropicrin on HDF cells at 24, 48 and $72 \mathrm{~h}$. Columns are plotted with standard deviation. $* * * *$ indicates the significance of the differences at the levels of $p<0.0001$.

Comparing the results between the two cell lines as shown in Fig. 3, indicated a selective cytotoxicity on the cancerous cells, which may confirm the anti-cancer effects of cynaropicrin. (Supplementary Comparison: 7).

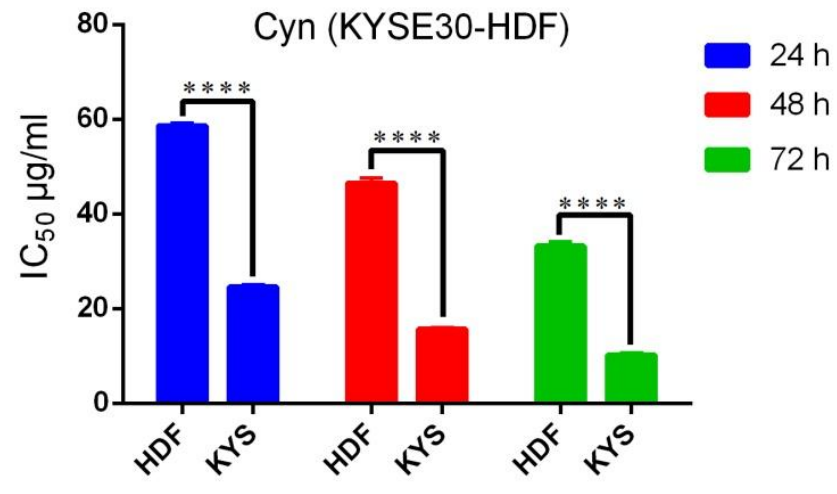

Fig. 3: Comparing the $\mathrm{IC}_{50}$ values of cynaropicrin on KYSE30 and HDF cells at 24, 48 and $72 \mathrm{~h}$. **** indicates significance of differences at the level of $p<0.0001$.
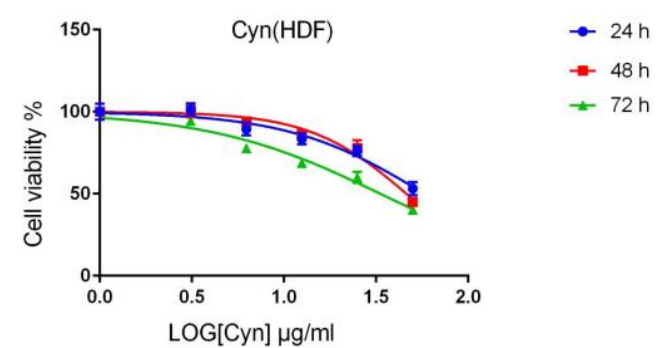
265 To investigate the cell death mechanism induced by cynaropicrin, flow cytometric analysis was performed after staining with FITC-annexin V and PI. Cells were treated with the 267 calculated $\mathrm{IC}_{50}$ value of cynaropicrin for $24 \mathrm{~h}$, equal to $25 \mu \mathrm{g} / \mathrm{ml}$, and stained after $15 \mathrm{~h}$. A control group was also treated with DMSO to find out the effects of solvent on induction of apoptosis. Pac was used as a positive control and untreated cells were considered as negative control. Flow cytometry results are presented in Fig. 4. (Supplementary A, C and D).

1

(1)

(1)


294

295

296

297

298

299

300

301

302

303

304

305

306

307

308

309

310

311

312

313

314

315

316

317

318

319

320

321

322
B

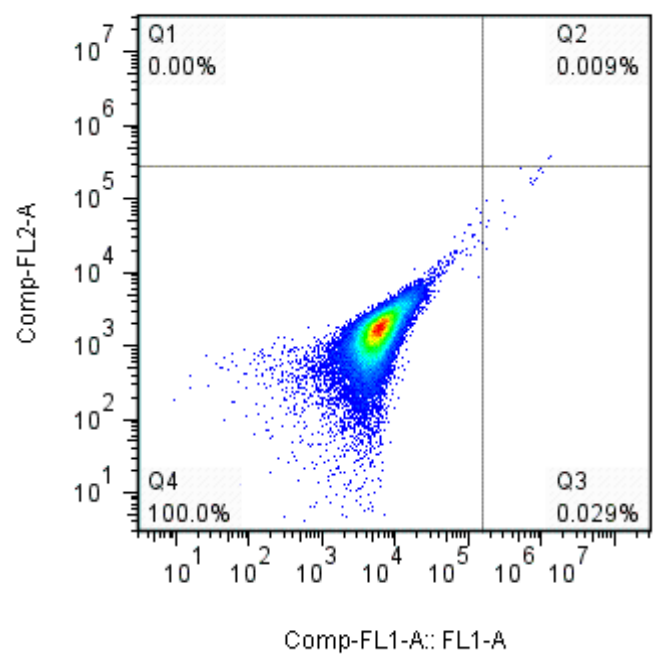

D

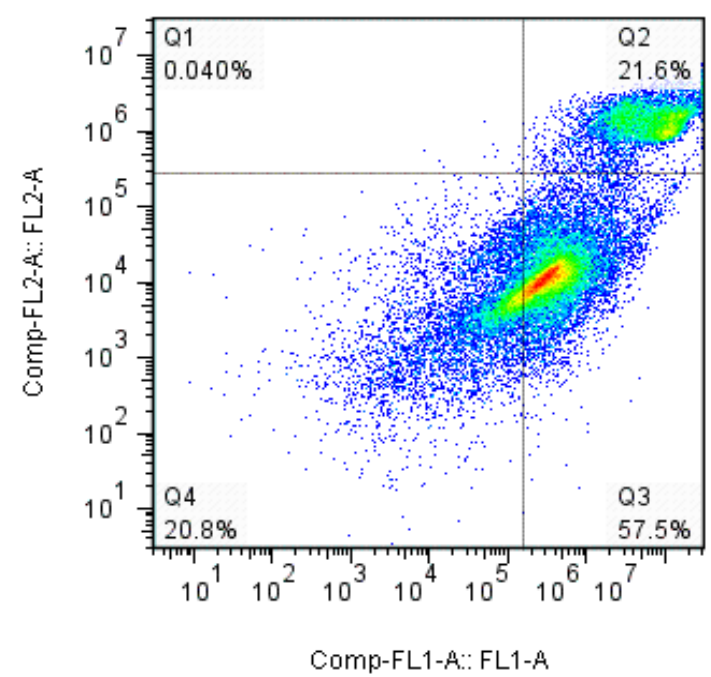

Comp-FL1-A:.: FL1-A
D
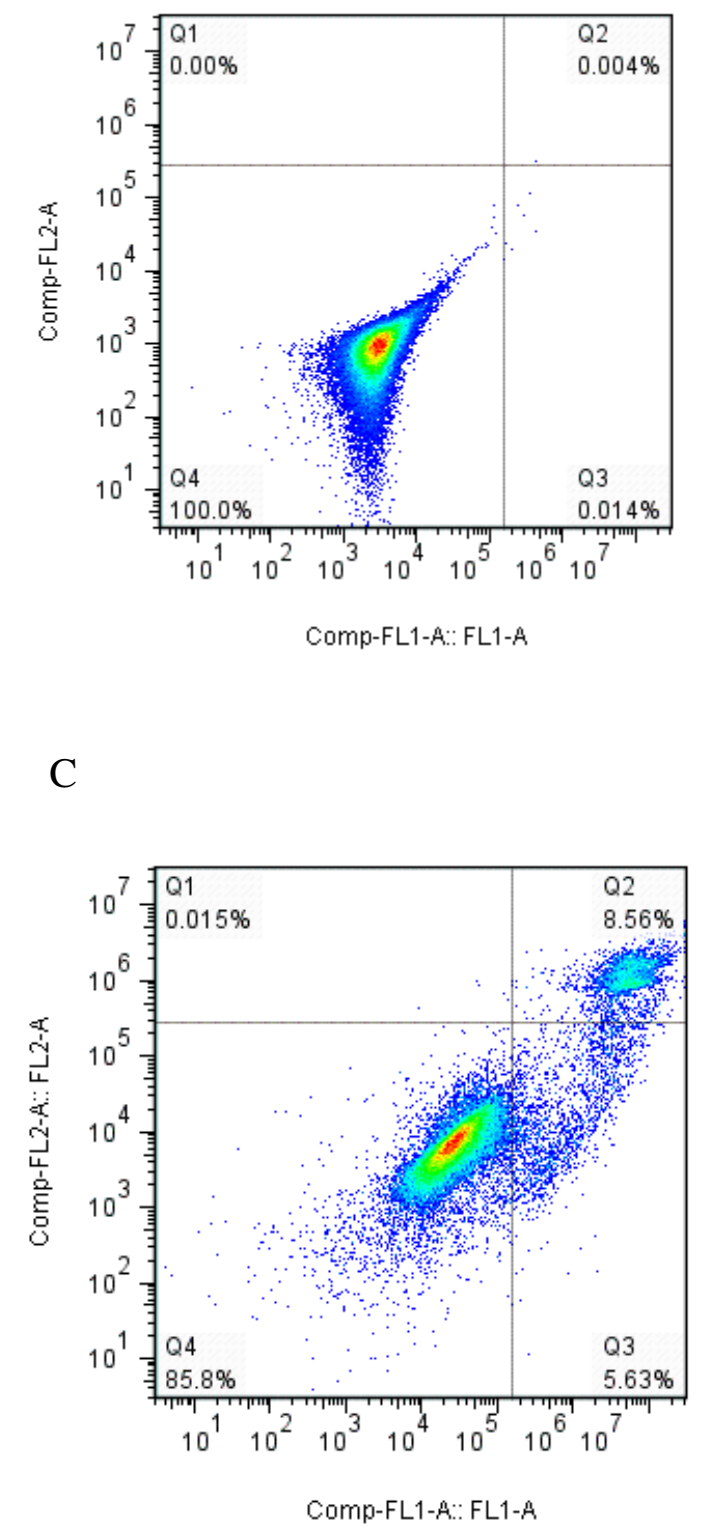

C 
323 The diagram of treated cells with cynaropicrin shows the presence of the majority of cells in

324 quarter 3, which indicates the occurrence of apoptosis in cells caused by cynaropicrin. The 325 cells in this quarter are annexin $\mathrm{V}^{+}$and $\mathrm{PI}^{-}$.

326

Cynaropicrin had synergistic effects with paclitaxel and 5-Fu

328 The median effect method of Chou-Talalay was used for investigating the synergistic effects of cynaropicrin with different drugs. To do so, acquiring data such as the $\mathrm{IC}_{50}$ and slope of dose-response diagrams for cynaropicrin, pac and 5-Fu at three time periods was necessary. As shown in Fig. 5, $\mathrm{IC}_{50}$ values estimated for pac, were equal to $7.93,5.92$ and $3.90 \mu \mathrm{g} / \mathrm{ml}$ and for 5-Fu, 79.98, 25.22 and $15.16 \mu \mathrm{g} / \mathrm{ml}$ at 24, 48 and $72 \mathrm{~h}$, respectively. (Supplementary

Fig. 5: Dose-response curves of A) pac and B) 5-Fu on KYSE30 cells. The graphs show the
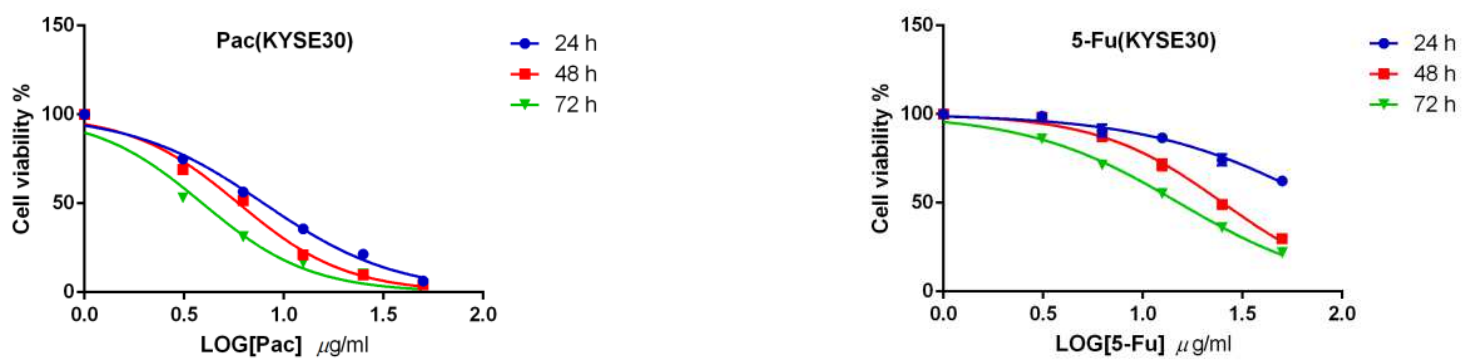
survival percentages of cells after treatment with different concentrations of drugs at 24,48 and $72 \mathrm{~h}$. 
351 The results indicated that pac had cytotoxic effects on KYSE30 cells in a time and

352 concentration-dependent manner. Moreover, 5-Fu showed similar but weaker effects, 353 especially on the first day of treatment. The combination experiments for cynaropicrin and 354 the two drugs were designed and cells were treated for 24,48 and $72 \mathrm{~h}$, based on the 355 principles of the median effect method. The results of both combinations, in all three time 356 periods, are presented in Figs. 6 and 7 for pac and 5-Fu, respectively. Diagrams were drawn 357 in the form of combination and dose reduction indices. With regard to pac-cyn combination, 358 the graphs represented an additive effect at low concentrations and an antagonistic effect at 359 high concentrations of combination within $24 \mathrm{~h}$. A synergistic effect at $48 \mathrm{~h}$ and a moderate 360 synergism at $72 \mathrm{~h}$ were observed. In both time periods, the CI value had been reduced at 361 higher concentrations and the synergism was strengthened. The results of the cynaropicrin362 pac combination in three periods are listed in table 1 in three sections $\mathrm{A}, \mathrm{B}$ and $\mathrm{C}$. (Supplementary S1, S2 and S3). 
378

379

380

381

382

383

384

385

386

387

388

389

390

391

392

393

394

395

396

397

398

399

400

401

402

403

404

405

406

407

408

409

410
B

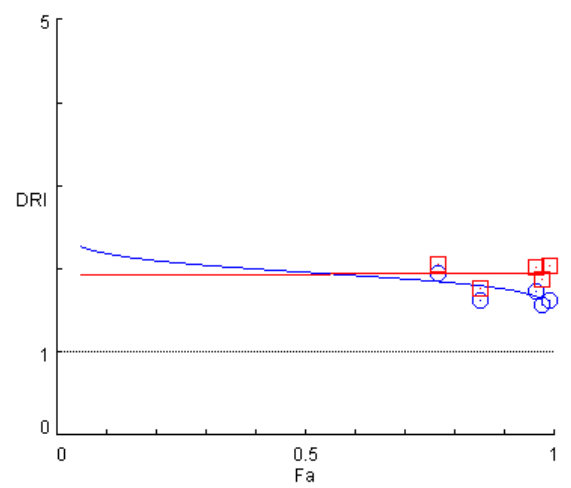

$\odot \operatorname{pac}$

- cyn

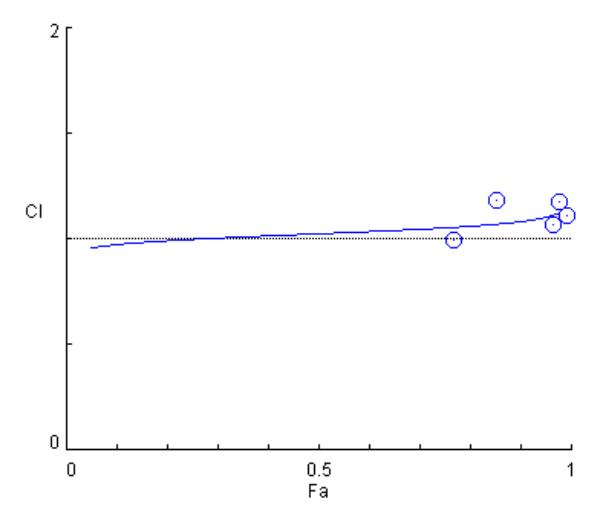

$\odot$ Paccyn

C

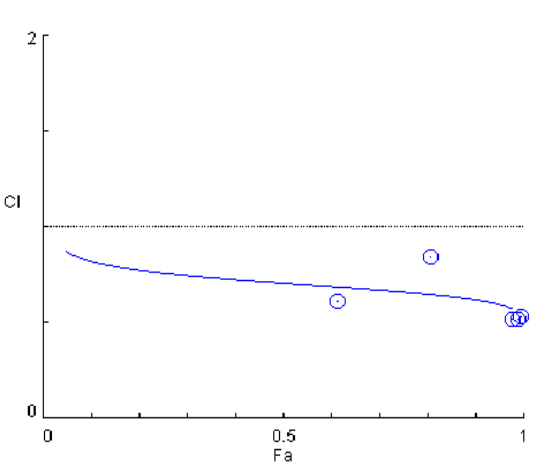

$\odot$ Paccin

D

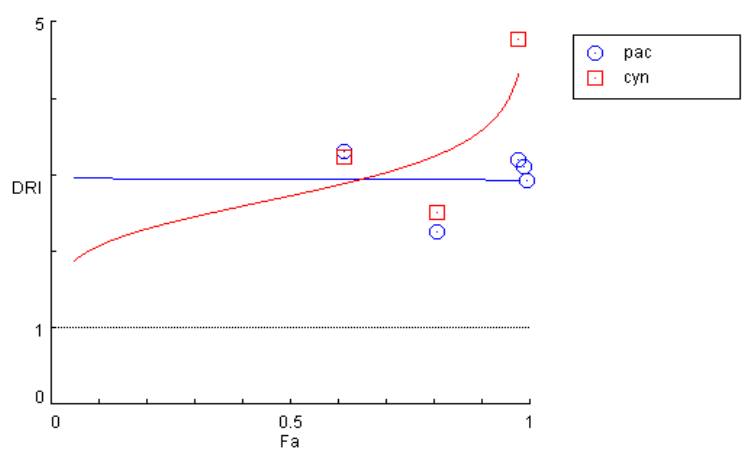

F

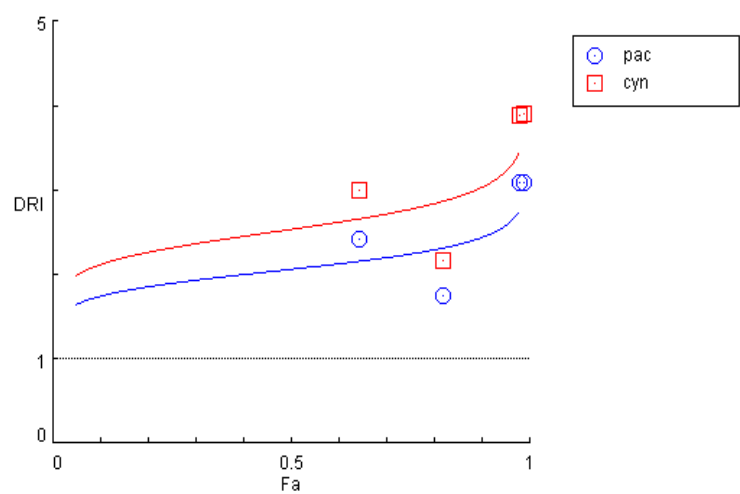

Fig. 6: A, C and E): Combination index diagrams show the simultaneous effects of pac and cynaropicrin on KYSE30 cells at 24, 48 and $72 \mathrm{~h}$, respectively. B, D and F): Dose reduction diagrams express a multiplier reduction in the dose of pac and cyn in a combination treatment over 24, 48 and 72 h. CI: Combination Index, Fa: Fraction affected, CI doesnot have unit. 
411 Table 1: CI and the DRI related to the combination of cyn-pac at A) 24, B) 48, C) $72 \mathrm{~h}$.

412

413 A

414

\begin{tabular}{|l|l|l|l|}
\hline $\mathbf{2 4} \mathbf{h}$ & CI value & DRI Cyn & DRI Pac \\
\hline $\mathrm{IC}_{50}$ & 1.02 & 1.93 & 1.96 \\
\hline $\mathrm{IC}_{75}$ & 1.05 & 1.94 & 1.85 \\
\hline $\mathrm{IC}_{90}$ & 1.08 & 1.94 & 1.75 \\
\hline $\mathrm{IC}_{95}$ & 1.10 & 1.94 & 1.69 \\
\hline
\end{tabular}

$415 \quad \mathrm{~B}$

\begin{tabular}{|l|l|l|l|}
\hline $\mathbf{4 8} \mathbf{h}$ & CI values & DRI Cyn & DRI Pac \\
\hline $\mathrm{IC}_{50}$ & 0.70 & 2.72 & 2.72 \\
\hline $\mathrm{IC}_{75}$ & 0.65 & 3.12 & 2.93 \\
\hline $\mathrm{IC}_{90}$ & 0.61 & 3.58 & 2.93 \\
\hline $\mathrm{IC}_{95}$ & 0.59 & 3.93 & 2.93 \\
\hline
\end{tabular}

416

$417 \quad \mathrm{C}$

\begin{tabular}{|l|l|l|l|}
\hline $\mathbf{7 2} \mathbf{h}$ & CI value & DRI Cyn & DRI Pac \\
\hline $\mathrm{IC}_{50}$ & 0.87 & 2.53 & 2.06 \\
\hline $\mathrm{IC}_{75}$ & 0.80 & 2.77 & 2.24 \\
\hline $\mathrm{IC}_{90}$ & 0.73 & 3.02 & 2.43 \\
\hline $\mathrm{IC}_{95}$ & 0.69 & 3.22 & 2.58 \\
\hline
\end{tabular}

418

419

420 The combination of cynaropicrin and $5-\mathrm{Fu}$ demonstrated a very strong synergism, so that $\mathrm{CI}=$

4210.13 and DRI for both substances in the $\mathrm{IC}_{50}$ was about 15. However, at higher

422 concentrations, the observed synergism was very weak, which ultimately ends to antagonism.

423 The results for this combination at 48 and $72 \mathrm{~h}$ indicated a synergism and a moderate

424 synergism, respectively. 
425 In Fig. 7, the CI and the DRI charts referring to cyn-5-Fu combinations at 24, 48 and $72 \mathrm{~h}$ are 426 presented. The results of the cynaropicrin-5-Fu combination in three periods are listed in 427 table 2 in three sections A, B and C. (Supplementary S4, S5 and S6).

428

429

430

431

432

433

434

435

436

437

438

439

440

441

442

443

444

445

446

447

448

449

450 
452

453

454

455

456

457

458

459

460

461

462

463

464

465

466

467

468

469

$470 \quad \mathrm{E}$

471

472

473

474

475

476

477

478

479 Fig. 7: A, C and E): Combination index diagrams showing the effects of 5-Fu and 480

481 482 over 24, 48 and 72 h. CI: Combination Index, Fa: Fraction affected, CI does not have unit.

483
B

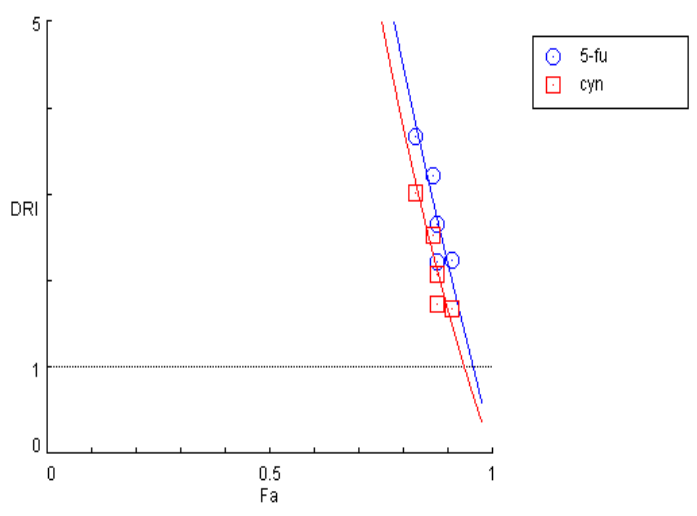

$\mathrm{D}$

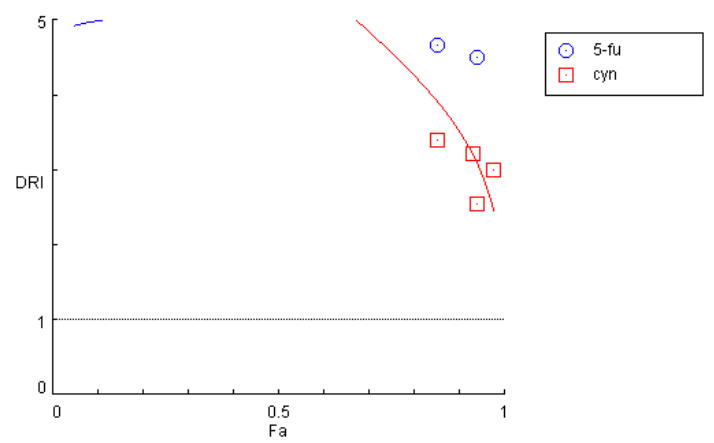

$\mathrm{F}$

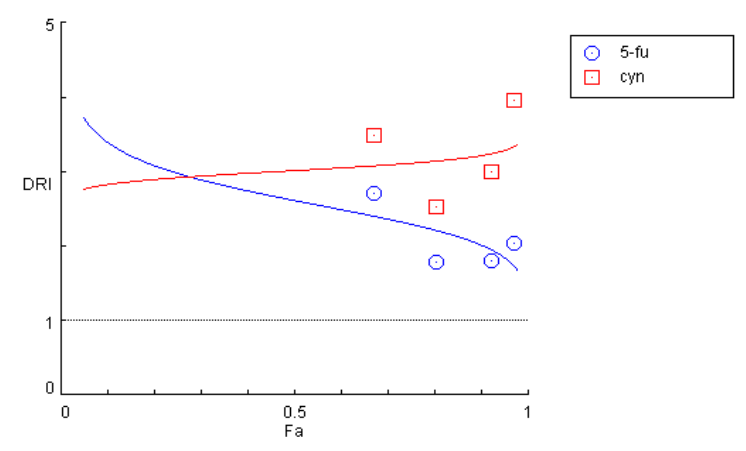

80 cynaropicrin on each other at 24, 48 and $72 \mathrm{~h}$. B, D and F): Dose reduction diagrams, 81 expressing a multiplier reduction in the dose of 5-Fu and Cyn in a combination treatment

83 Table 2: CI and the DRI related to the combination of cyn-5-Fu at A) 24, B) 48, C) $72 \mathrm{~h}$. 


\begin{tabular}{|l|l|l|l|}
\hline $\mathbf{2 4} \mathbf{h}$ & CI value & DRI Cyn & DRI 5-Fu \\
\hline $\mathrm{IC}_{50}$ & 0.13 & 15.26 & 15.07 \\
\hline $\mathrm{IC}_{75}$ & 0.37 & 5.03 & 5.75 \\
\hline $\mathrm{IC}_{90}$ & 1.07 & 1.66 & 2.19 \\
\hline $\mathrm{IC}_{95}$ & 2.15 & 0.78 & 1.14 \\
\hline
\end{tabular}

485

$486 \quad$ B

487

\begin{tabular}{|l|l|l|l|}
\hline $\mathbf{4 8} \mathbf{h}$ & CI value & DRI Cyn & DRI 5-Fu \\
\hline $\mathrm{IC}_{50}$ & 0.36 & 5.92 & 5.18 \\
\hline $\mathrm{IC}_{75}$ & 0.40 & 4.56 & 5.27 \\
\hline $\mathrm{IC}_{90}$ & 0.47 & 3.51 & 5.37 \\
\hline $\mathrm{IC}_{95}$ & 0.52 & 2.93 & 5.44 \\
\hline
\end{tabular}

$488 \quad \mathrm{C}$

\begin{tabular}{|l|l|l|l|}
\hline $\mathbf{7 2} \mathbf{h}$ & CI value & DRI Cyn & DRI 5-Fu \\
\hline $\mathrm{IC}_{50}$ & 0.71 & 3.01 & 2.61 \\
\hline $\mathrm{IC}_{75}$ & 0.75 & 3.11 & 2.29 \\
\hline $\mathrm{IC}_{90}$ & 0.80 & 3.21 & 2.01 \\
\hline $\mathrm{IC}_{95}$ & 0.84 & 3.28 & 1.83 \\
\hline
\end{tabular}

489

490

Table 2: CI and the DRI related to the combination of cyn-5-Fu at A) 24, B) 48, and C) $72 \mathrm{~h}$.

491

492

493

494

495

496

497 
The high incidence and mortality rate of esophageal cancer, which is one of the common cancers of the digestive system in Asia (Ferlay et al., 2010), indicate the serious threats of this malignancy (Napier et al., 2014). The absence of a comprehensive diagnostic system leads to late detection, poor prognosis and high mortality rates (Polednak, 2003; Qureshi et al., 2009; Pourhoseingholi et al., 2015). Some predictions suggest a decrease in the incidence of cancer in the coming decades, but it does not include esophageal cancer. The incidence of esophageal cancer is expected to increase by $140 \%$ up to 2025 (Lambert et al., 2007). In the present study, the toxicity and anti-cancer effects of cynaropicrin were investigated on KYSE30 cells and the mechanism of cell death induced by this compound was examined. The synergistic effects of cynaropicrin with common chemotherapeutic drugs used for esophageal cancer, pac and 5-Fu, were also investigated and calculated by Chou-Talalay median effect method. The results indicated significant differences $(p<0.0001)$ in cytotoxic effects of cynaropicrin on normal HDF cells compared to cancerous cell line, which proves selective toxicity and anti-cancer effects of this compound on KYSE30 cells.

As mentioned earlier, many studies have been carried out on cynaropicrin in which several investigations are related to cytotoxic and anti-cancer effects of this compound. Some researchers have focused only on cytotoxic effects of cynaropicrin (Choi et al., 2005; Yang et al., 2008; Bruno et al., 2005; Ha et al., 2003; Kang et al., 2007 and Butturini et al., 2013). In these studies, cytotoxic effects of cynaropicrin were proven on different cell lines including 518 prostate, breast, stomach, colon, lung, ovary and cervix cancerous cells and also myeloma cells. The lowest and highest reported $\mathrm{IC}_{50}$ values were $0.83 \mu \mathrm{M}$ for HCT15 (colon cancer) and $24.51 \mu \mathrm{M}$ for A549 (lung cancer), respectively. In none of these studies, the selective anti-cancer effects of cynaropicrin were investigated. 
522 In a study by Cho and colleagues (2004b), several leukocyte cancer cell lines including U937, 1-EO1 and Jurkat T cells were treated with cynaropicrin and its toxic effects were confirmed.

524 The treatment was also performed on HDF-1 and Chang liver cells (human liver cells) as normal cell lines. The significant difference observed between the $\mathrm{IC}_{50}$ values of cancerous and normal cells confirms the anti-cancer effects of this compound (Cho et al., 2004b). In a similar study, various cancer cell lines were treated with cynaropicrin. The lowest and highest $\mathrm{IC}_{50}$ values were related to SK-MEL (melanoma) equal to $5.77 \mu \mathrm{M}$ and SK-OV-3 (ovary cancer) equal to $18.18 \mu \mathrm{M}$, respectively. VERO cell line (kidney epithelial cells from African green monkey) as normal cells, was used to confirm the anti-cancer effects of cynaropicrin. No significant difference was observed between its $\mathrm{IC}_{50}$ values on normal and cancerous cells (Muhammad et al., 2003). It can be concluded that VERO cells were not an appropriate control in this study. The findings of these reports are in agreement with the results obtained in present study.

Chen and colleagues (2007) proved that the activation of EGFR-encoding gene contributes to the creation and progression of ESCC. The role of inhibiting this pathway in the treatment of esophageal cancer was discovered using erlotinib and afatinib inhibitors. For this purpose, seven different ESCC cell lines were examined. Observations indicated that these drugs inhibited the pathway and led to a decrease in the growth of cancerous cells. However, KYSE30, TE8 and KYSE250 were introduced as cell lines which significantly had less growth inhibition, and were more resistant than other ESCC cell lines used in their study

542 (Chen et al., 2017). This result can be a reason for the numerical difference between $\mathrm{IC}_{50}$ values of cynaropicrin on KYSE30 cells compared with other cancerous cell lines.

544 The occurrence of apoptosis after treatment with cynaropicrin was confirmed by flow cytometry. Several other studies have also shown the apoptosis inducing effects of cynaropicrin in different cell lines. For example, according to Cho et al. the production of 
reactive oxygen species by cynaropicrin led to induction of apoptosis. To prove this, cells were treated simultaneously with cynaropicrin and two scavengers of reactive oxygen species including L-cysteine and $\mathrm{N}$-acetyl-L-cysteine. The two scavengers inhibited the morphological changes and DNA fragmentation induced by cynaropicrin (Cho et al., 2004b). Moreover, in a study by Butturini et al. cynaropicrin was considered as an inhibitor of STAT3 activation and IL-6 production stimulus. They showed that cynaropicrin as the receptor of the Michaelis-Menten reaction, induces the addition of glutathione to STAT3 and inhibits this transcription factor. The inhibition of STAT3 leads to suppressing the expression of two anti-apoptotic genes, including BCL2 and Survivin in DU 145 cells. STAT3 is active in a variety of cancers and plays an important role in inhibition of apoptosis and inducing drug resistance (Butturini et al., 2013).

As noted above, Chou-Talalay method was used to investigate the combination effects of cynaropicrin with pac and 5-Fu drugs. The reason for this selection is the advantages of this method including: detection of various types of behaviors in combination (synergism, additive and antagonism), significant reduction in drug consumption, time saving, estimation of the behavior of materials in combination with the lowest number of data, presenting results numerically and independent of unit, and in particular, being functional at both in vitro and in vivo levels (Chou, 2006; Chou, 2008). Additive effects were observed in the combination of cynaropicrin with pac using this method at $24 \mathrm{~h}$. The strongest synergistic effects were revealed at $48 \mathrm{~h}$. DRI for pac was about three times, and for cynaropicrin was about four times. These synergistic effects were also observed at $72 \mathrm{~h}$ at which DRI for pac was greater than two times and for cynaropicrin it was higher than three times. It must be noted that having a dose reduction in combination does not merely mean synergistic effects. So that, even in the case of minor antagonism, there is a possibility of dose reduction. Therefore, CI is

571 the primary reference for the diagnosis of synergistic effects. All in all, cynaropicrin had a 
synergistic effect in combination with pac in a time-dependent manner. In the combination of cynaropicrin with 5-fluorouracil in $\mathrm{IC}_{50}$, the $\mathrm{CI}$ was equal to 0.13 with a $\mathrm{DRI}=$ of about 15 , that indicate a very strong synergistic effect. However, our data showed that with an increase in $\mathrm{IC}$, the $\mathrm{CI}$ increases. So that, in $\mathrm{IC}_{95}$ the $\mathrm{CI}$ reached over two, which indicates the antagonistic effect. Hence, cynaropicrin and 5-Fu have the most synergistic effects at lower concentrations. At $48 \mathrm{~h}$, this combination also showed a good synergistic effect in $\mathrm{IC}_{50}$ in which the CI was equal to 0.36 . Regarding the remaining synergistic effects, even at $\mathrm{IC}_{95}$ at $48 \mathrm{~h}$, it can be concluded that the synergistic effects of cynaropicrin and 5-Fu at high concentrations are time-dependent. At $72 \mathrm{~h}$, synergistic effects were observed for all concentrations of the combination. To summarize, combination of both drugs with cynaropicrin had the most logical synergistic effects within $48 \mathrm{~h}$. However, the strongest synergistic effects on the combination of cynaropicrin and 5-Fu was observed at $24 \mathrm{~h}$.

Study of Butturini et al. (2013) is the only trial in which the combination of cynaropicrin with chemotherapy drugs was examined. In this study, the effects of cynaropicrin in combination with cisplatin and docetaxel were investigated on a prostate cancer cell line (DU 145). In both cases, the synergistic effects of cynaropicrin were observed (Butturini et al., 2013). In another study, the effects of DMSO on platinum compounds such as cisplatin and carboplatin were investigated (Hall et al., 2014). As a result, it was reported that DMSO reacts with platinum and prevents the toxicity of these compounds (Hall et al., 2014). According to this result, the cisplatin combination with cynaropicrin in the study of Butturini and colleagues (2013), requires further approval with another suitable solvent for cynaropicrin. Based on the Chou-Talalay method, the smaller CI will have a greater DRI, but in the case of combination of docetaxel with cynaropicrin in the latest study, the result is quite the opposite; when the strongest synergistic effect was observed, there was the lowest dose reduction and in the weakest synergistic effect, the highest reduction in the dosage were recorded, which does not 
seem to be logical (Butturini et al., 2013). Therefore, the results of the combination of

598

599

600

601

602

603

604

605

606

607

608

609

610

611

612

613

614

615

616

617

618

619

620

621

622 docetaxel and cynaropicrin also need to be reviewed.

\section{Conclusion}

To conclude, the present study reported cynaropicrin as a potent candidate with anti-cancer properties for treatment of ESCC. It has a very high potential for combinational therapy which can reduce the dose of chemotherapy drugs and subsequently reduce their side effects. Nevertheless, further studies are needed to investigate the effects of cynaropicrin on other cancer cell lines, as well as its synergistic effects with other chemotherapy drugs in both in vitro and in vivo models.

\section{Acknowledgements}

Authors would like to express their sincere thanks to Dr. Fatemeh Homaei Shandiz, Dr. Kordiyeh Hamidi, Nahid Arghiani and Mahboobeh Kazemi for their scientific and technical supports which greatly improved the content.

\section{Funding}

This research was supported by a grant (no: 43291) from Ferdowsi University of Mashhad.

\section{Authors Contributions}

M.M.M.and A.R.B. conceived and designed the experiments, and supervised the project; S.N. conducted the experiments and wrote the manuscript; S.N. and N.G. analyzed the data; M.I. and A.S.extracted and purified the tested plant composition; M.M.M. and A.S. proofread the manuscript. All authors discussed the results and commented on the manuscript. The authors declare that all data were generated in-house and that no paper mill was used. 


\section{Declarations}

624

625 Consent to participate:

626 The authors declare consent to participate in this study.

627

628 Consent for publication:

629 The authors declare consent to publish this study.

630

631 Conflict of interest:

632 The authors declare that they have no conflict of interest.

633

634 Ethics approval:

635 This article does not contain any studies with human participants or animals performed by 636 any of the authors.

637

638

639

640

641

642

643

644

645

646

647

648 


\section{References}

Abnet, C. C., Arnold, M., \& Wei, W. Q. (2018). Epidemiology of esophageal squamous cell carcinoma. Gastroenterology, 154(2), 360-373.

Ahmad, R., Ahmad, N., Naqvi, A. A., Shehzad, A., \& Al-Ghamdi, M. S. (2016). Role of traditional Islamic and Arabic plants in cancer therapy. Journal of Traditional and Complementary Medicine, 7(2), 195-204.

Aghcheli, K., Marjani, H. A., Nasrollahzadeh, D., Islami, F., Shakeri, R., Sotoudeh, M., ... \& Mohtashami, S. (2011). Prognostic factors for esophageal squamous cell carcinoma-a population-based study in Golestan Province, Iran, a high incidence area. PLoS One, 6(7), e22152.

Akao,Y., Tanaka, Y. T., Tanaka, K., Kojima, H., Hamada, T., Masutani, T. \& Tsuboi, M. (2013). Cynaropicrin from Cynara scolymus L. suppresses photoaging of skin by inhibiting the transcription activity of nuclear factor-kappa B. Bioorganic \& Medicinal Chemistry Letters. 23:518-523.

Akbari, M. R., Malekzadeh, R., Nasrollahzadeh, D., Amanian, D., Sun, P., Islami, F., \& Ghadirian, P. (2006). Familial risks of esophageal cancer among the Turkmen population of the Caspian littoral of Iran. International Journal of Cancer, 119(5), 1047-1051.

Akkol, E. K., Arif, R., Ergun, F., \& Yesilada, E. (2009). Sesquiterpene lactones with antinociceptive and antipyretic activity from two Centaurea species. Journal of Ethnopharmacology, 122(2), 210-215.

Alam, F., Islam, M. A., Kamal, M. A., \& Gan, S. H. (2018). Updates on managing type 2 diabetes mellitus with natural products: towards antidiabetic drug development. Current Medicinal Chemistry, 25(39), 5395-5431.

Arnold, M., Soerjomataram, I., Ferlay, J., \& Forman, D. (2015). Global incidence of oesophageal cancer by histological subtype in 2012. Gastroenterology, 64(3), 381-387.

Ashton, J. C. (2015). Drug combination studies and their synergy quantification using the Chou-Talalay method letter. Cancer Research, 75(11), 2400-2400.

Bachelier, A., Mayer, R., \& Klein, C. D. (2006). Sesquiterpene lactones are potent and irreversible inhibitors of the antibacterial target enzyme MurA. Bioorganic \& Medicinal Chemistry Letters, 16(21), 5605-5609.

Baruah, N. C., Sarma, J. C., Barua, N. C., Sarma, S., \& Sharma, R. P. (1994). Germination and growth inhibitory sesquiterpene lactones and a flavone from Tithoni adiversifolia. Phytochemistry, 36(1), 29-36.

Bensouici, C., Kabouche, A., Kabouche, Z., Touzani, R., \& Bruneau, C. (2012).

Sesquiterpene lactones and flavonoids from Centaurea foucauldiana. Chemistry of Natural Compounds, 48(3), 510-511. 

H. (2005). Cytotoxic activity of some natural and synthetic sesquiterpene lactones. Planta

Butler, M. S. (2004). The role of natural product in chemistry in drug discovery. Journal of Natural Products. 67: 2141-2153.

Butturini, S., Mariotto, E., Alessandra Carcereri de Prati, Chiavegato, G., Rigo, A., Cavalieri, E. \& Darra, E. (2013). Mild oxidative stress induces S-glutathionylation of STAT3 and enhances chemosensitivity of tumoural cells to chemotherapeutic drugs. Free Radical Biology and Medicine, 65, 1322-1330.

Camphausen, K., Moses, M. A., Beecken, W. D., Khan, M. K., Folkman, J., O'Reilly, M. S. (2001). Radiation therapy to a primary tumor accelerates metastatic growth in mice. Cancer Research. 61: 2207-11.

Cardona, L., Garcia, B., Navarro, F. I., \& Pedro, J. R. (1994). Sesquiterpene lactones from Centaurea paui. Natural Product Letters, 5(1), 47-54.

Chen, L., \& Pan, J. (2017). Dual cyclin-dependent kinase 4/6 inhibition by PD-0332991 induces apoptosis and senescence in oesophageal squamous cell carcinoma cells. British Journal of Pharmacology, 174(15), 2427-2443.

Chesney, M. A., Morin, M., and Sherr, L. (2000). Adherence to HIV combination therapy. Social Science and Medicine. 50: 1599-1605.

Chicca, A., Tebano, M., Adinolfi, B., Ertugrul, K., Flamini, G., \& Nieri, P. (2011). Antiproliferative activity of aguerin $\mathrm{B}$ and a new rare nor-guaianolide lactone isolated from the aerial parts of Centaurea deflexa. European Journal of Medicinal Chemistry, 46(7), 30663070 .

Cho, J. Y., Baik, K. U., Jung, J. H., \& Park, M. H. (2000). In vitro anti-inflammatory effects of cynaropicrin, a sesquiterpene lactone, from Saussurea lappa. European Journal of Pharmacology, 398(3), 399-407.

Cho, J. Y., Kim, A. R., Joo, H. G., Kim, B. H., Rhee, M. H., Yoo, E. S., ... \& Jung, J. H. (2004). Cynaropicrin, a sesquiterpene lactone, as a new strong regulator of CD29 and CD98 functions. Biochemical and Biophysical Research Communications, 313(4), 954-961.

Cho, J. Y., Kim, A. R., Jung, J. H., Chun, T., Rhee, M. H. \& Yoo, E. S. (2004b). Cytotoxic and pro-apoptotic activities of cynaropicrin, a sesquiterpene lactone, on the viability of leukocyte cancer cell lines. European Journal of Pharmacology, 492(2), 85-94.

Cho, J. Y., Park, J., Yoo, E. S., Baik, K. U., Jung, J. H., Lee, J., \& Park, M. H. (1998). Inhibitory effect of sesquiterpene lactones from Saussurea lappa on tumor necrosis factor- $\alpha$ production in murine macrophage-like cells. Planta Medica, 64(07), 594-597.

Choi, S. Z., Choi, S. U. \& Lee, K. R. (2005). Cytotoxic sesquiterpene lactones from Saussurea calcicola. Archives of Pharmacal Research, 28(10), 1142-1146. 
Chou, T. C. (2010). Drug combination studies and their synergy quantification using the

Chou-Talalay method. Cancer Research, 70(2), 440-446.

Chou, T. C. (2008). The Mass-Action-Law Based GPS Concept for Bio-Informatics, 1-1.

Chou, T. C. (2006). Theoretical basis, experimental design, and computerized simulation of synergism and antagonism in drug combination studies. Pharmacological Reviews, 58(3), 621-681.

Chougule, P., Pawar, R., Limaye, D., Joshi, Y. M., \& Kadam, V. (2012). In-vitro antioxidant activity of ethanolic extract of Centaurea behen. Journal of Applied Pharmaceutical Science, 02, 106-110.

Cragg, G. M., Newman, D. J. (2005). Biodiversity: A continuing source of novel drug leads. Pure and Applied Chemistry. 77: 7-24.

da Silva, C. F., Batista, D. D. G. J., De Araujo, J. S., Batista, M. M., Lionel, J., de Souza, E. M., ... \& Zimmermann, S. (2013). Activities of psilostachyin A and cynaropicrin against Trypanosoma cruzi in vitro and in vivo. Antimicrobial Agents and Chemotherapy, 57(11), 5307-5314.

Devita, V. T., Young, R. C., \& Canellos, G. P. (1975). Combination versus single agent chemotherapy: a review of the basis for selection of drug treatment of cancer. Cancer, 35(1), 98-110.

Drab, A. I., Nurmukhametova, K. A., Pak, R. N., \& Adekenov, S. M. (2005). Antiopisthorchotic action of Saussurea salsa extract. Pharmaceutical Chemistry Journal, $39(8)$, 425-427.

Elrayess, R. A., \& El-Hak, H. N. G. (2019). Anticancer natural products: A review. Cancer Studies Molecular Medicine Open Journal. 5(1), 14-25.

Enzinger, P. C., \& Mayer, R. J. (2003). Esophageal cancer. New England Journal of Medicine, 349(23), 2241-2252.

Ferlay, J., Shin, H.R., Bray, F., Forman, D., Mathers, C., Parkin, D.M. (2010). Estimates of worldwide burden of cancer in 2008: GLOBOCAN 2008. International Journal of Cancer, 127:2893-917.

Ferlay, J., Soerjomataram, I., Dikshit, R., Eser, S., Mathers, C., Rebelo, M., Bray, F. (2015). Cancer incidence and mortality worldwide: Sources, methods and major patterns in GLOBOCAN 2012. International Journal of Cancer, 136(5): E359-E386.

Ferlay, J., Soerjomataram, I., Ervik, M., Dikshit, R., Eser, S., \& Mathers, C. (2013). GLOBOCAN 2012: estimated cancer incidence, mortality and prevalence worldwide in 2012.

Forgo, P., Zupko, I., Molnar, J., Vasas, A., Dombi, G., \& Hohmann, J. (2012). Bioactivityguided isolation of antiproliferative compounds from Centaurea jacea L. Fitoterapia, 83(5), 921-925. 
Garbacki, N., Gloaguen, V., Damas, J., Bodart, P., Tits, M., \& Angenot, L. (1999). Anti-

inflammatory and immunological effects of Centaurea cyanus flower-heads. Journal of Ethnopharmacology, 68(1-3), 235-241.

Georgiadou, E., Skaltsa, H., Lazari, D., Garcia, B., \& Harvala, C. (2000). A novel eudesmanolide from Centaurea thessala Hausskn. Ssp. Drakiensis (Freyn \& Sint.) Georg. Natural Product Letters, 14(3), 167-173.

Ha, T. J., Jang, D. S., Lee, J. R., Lee, K. D., Lee, J., Hwang, S. W., Jung, H. J., Nam, S. H., Park, K. H. \& Yang, M. S. (2003). Cytotoxic effects of sesquiterpene lactones from the flowers of Hemisteptia lyrata B. Archives of Pharmacol Research, 26(11): 925-928.

Haefner, B. (2003). Drugs from the deep: Marine natural products as drug candidates. Drug Discovery Today. 8: 536-544.

Hall, M. D., Telma, K. A., Chang, K. E., Lee, T. D., Madigan, J. P., Lloyd, J. R., ... \& Gottesman, M. M. (2014). Say no to DMSO: dimethylsulfoxide inactivates cisplatin, carboplatin, and other platinum complexes. Cancer Research, 74(14), 3913-3922.

Hayata, M., Watanabe, N., Kamio, N., Tamura, M., Nodomi, K., Tanaka, K., ... \& Ueda, K. (2019). Cynaropicrin from Cynara scolymus L. suppresses Porphyromonas gingivalis LPSinduced production of inflammatory cytokines in human gingival fibroblasts and RANKLinduced osteoclast differentiation in RAW264. 7 cells. Journal of Natural Medicines, 73(1), 114-123.

Heinrich, M., Robles, M., West, J. E., Ortiz de Montellano, B. R. \& Rodriguez, E. (1998). Ethnopharmacology of Mexican asteraceae (compositae). Annual Review of Pharmacology and Toxicology, 38(1): 539-565.

Herszenyi, L., Tulassay, Z. (2010). Epidemiology of gastrointestinal and liver tumors. European Review for Medical and Pharmacological Sciences, 14:249-258.

Herz, W. (1977). Sesquiterpene lactones in the Compositae. Heywood, V, H, Harborne, J, B,, Turner, B, Led (s). The Biology and Chemistry of the Compositae, 1, 337-357.

Hou, H., Meng, Z., Zhao, X., Ding, G., Sun, M., Wang, W., \& Wang, Y. (2019). Survival of esophageal cancer in China: a pooled analysis on hospital-based studies from 2000 to 2018. Frontiers in Oncology, 9, 548.

Huang, C. Y., Ju, D. T., Chang, C. F., Reddy, P. M., \& Velmurugan, B. K. (2017). A review on the effects of current chemotherapy drugs and natural agents in treating non-small cell lung cancer. Biomedicine, 7(4).

Hu, X. Q., Sun, Y., Lau, E., Zhao, M., \& Su, S. B. (2016). Advances in synergistic combinations of Chinese herbal medicine for the treatment of cancer. Current Cancer Drug Targets, 16(4), 346-356. 

statistics. CA: A Cancer Journal for Clinicians, 61(2), 69-90.

Jemal, A., Murray, T., Ward, E., Samuels, A., Tiwari, R. C., Ghafoor, A., et al. (2005). Cancer statistics. CA: A Cancer Journal for Clinicians, 55:10-30.

Jia, J., Zhu, F., Ma, X., et al. (2009). Mechanisms of drug combinations: interaction and network perspectives. Nature Reviews Drug Discovery. 8: 111-28.

Jukema, J. W., andvanderHoorn, J. W. (2004). Amlodipine and atorvastatin in atherosclerosis: a review of the potential of combination therapy. Expert Opinion on Pharmacotherapy. 5: 459-468.

Jung, J. W., Hwang, S. Y., Hwang, J. S., Oh, E. S., Park, S., Han, I. O. (2007). Ionising radiation induces changes associated with epithelial-mesenchymal transdifferentiation and increased cell motility of A549 lung epithelial cells. European Journal of Cancer. 43: 121424.

Kang, K., Lee, H. J., Kim, C. Y., Lee, S. B., Tunsag, J., Batsuren, D., \& Nho, C. W. (2007). The chemopreventive effects of Saussurea salicifolia through induction of apoptosis and phase II detoxification enzyme. Biological and Pharmaceutical Bulletin, 30(12), 2352-2359.

Kaur, R., Kapoor, K., \& Kaur, H. (2011). Plants as a source of anticancer agents. Journal of Natural Product and Plant Resources, 1(1), 119-124.

Khare, C. P. (2004). Indian herbal remedies: rational Western therapy, ayurvedic, and other traditional usage, Botany. Springer Science \& Business Media.

Kinghorn, A. D., Chin, Y. W., \& Swanson, S. M. (2009). Discovery of natural product anticancer agents from biodiverse organisms. Current Opinion in Drug Discovery \& Development, 12(2), 189.

Koca, U., Toker, G., \& Akkol, E. K. (2009). Assessment of the extracts of Centaureatchihatcheffii Fischer for anti-inflammatory and analgesic activities in animal models. Tropical Journal of Pharmaceutical Research, 8(3).

Kolli, E. H., Leon, F., Benayache, F., Estevez, S., Quintana, J., Estevez, F., ... \& Benayache, S. (2012). Cytotoxic sesquiterpene lactones and other constituents of Centaurea omphalotricha. Journal of the Brazilian Chemical Society, 23(5), 977-983.

Komal, K., Chaudhary, S., Yadav, P., Parmanik, R., \& Singh, M. (2019). The therapeutic and preventive efficacy of curcumin and its derivatives in esophageal cancer. Asian Pacific Journal of Cancer Prevention, 20(5), 1329.

Lagergren, J., Smyth, E., Cunningham, D., \& Lagergren, P. (2017). Oesophageal cancer. The Lancet, 390(10110), 2383-2396.

Lambert, R., Hainaut, P. (2007). The multidisciplinary management of gastrointestinal cancer. Epidemiology of oesophagogastric cancer. Best Practice \& Research: Clinical Gastroenterology, 21:921-945. 
Liang, H., Fan, J. H., \& Qiao, Y. L. (2017). Epidemiology, etiology, and prevention of esophageal squamous cell carcinoma in China. Cancer Biology \& Medicine, 14(1), 33-41.

Lim, I. K., Hong, K. W., Kwak, I. H., Yoon, G., \& Park, S. C. (2000). Cytoplasmic retention of p-Erk1/2 and nuclear accumulation of actin proteins during cellular senescence in human diploid fibroblasts. Mechanisms of Ageing and Development, 119(3), 113-130.

Liu, T., Zhang, J., Han, X., Xu, J., Wu, Y., \& Fang, J. (2019). Promotion of HeLa cells apoptosis by cynaropicrin involving inhibition of thioredox in reductase and induction of oxidative stress. Free Radical Biology and Medicine, 135, 216-226.

Majidi, A., Salimzadeh, H., Beiki, O., Delavari, F., Majidi, S., Delavari, A., \& Malekzadeh, R. (2017). Cancer research priorities and gaps in Iran: the influence of cancer burden on cancer research outputs between 1997 and 2014. Public Health, 144, 42-47.

Malhotra, G. K., Yanala, U., Ravipati, A., Follet, M., Vijayakumar, M., \& Are, C. (2017).

Global trends in esophageal cancer. Journal of Surgical Oncology, 115(5), 564-579.

Mansoori, B., Mohammadi, A., Doustvandi, M. A., Mohammadnejad, F., Kamari, F., Gjerstorff, M. F., ... \& Hamblin, M. R. (2019). Photodynamic therapy for cancer: Role of natural products. Photodiagnosis and Photodynamic Therapy, 26, 395-404

Mehndiratta, S., Kumar, S., Meena, A. K., Koul, S., Suri, O., \& Dhar, K. L. (2011). A Review on plants a useful source of anti-cancer drugs. Journal of Pharmacy Research, 4, 264-71.

Mir, M. M., Dar, N. A., Gochhait, S., Zargar, S. A. \& Ahangar, A. G. (2005) p53 mutation profile of squamous cell carcinomas of the esophagus in Kashmir (India): a high incidence area. International Journal of Cancer 116: 62-68.

Mishra, B. B., Tiwari, V. K. (2011). Natural products: An evolving role in future drug discovery. European Journal of Medicinal Chemistry. 46: 4769-4807.

Mokhtari, R. B., Homayouni, T. S., Baluch, N., Morgatskaya, E., Kumar, S., Das, B., \&Yeger, H. (2017). Combination therapy in combating cancer. Oncotarget, 8(23), 38022.

Mokoka, T. A., Xolani, P. K., Zimmermann, S., Hata, Y., Adams, M., Kaiser, M., ... \& Brun, R. (2013). Antiprotozoal screening of 60 South African plants, and the identification of the antitrypanosomal germacranolides schkuhrin I and II. Planta Medica, 79(14), 1380-1384.

Mosaddegh, M., Tavakoli, M., \& Behzad, S. (2018). Constituents of the aerial parts of Centaurea behen. Chemistry of Natural Compounds, 54(5), 1015-1017.

Moyana, T. N., Janoski, M. (1996). Recent trends in the epidemiology of esophageal cancer. Comparison of epidermoid- and adenocarcinomas. Annals of Clinical \& Laboratory Science, 26:480-486.

Mozaffarian, V. (2012). Identification of medicinal and aromatic plants of Iran. Farhang Moaser Publishers. 

Vicoapentanema. Phytotherapy Research 17(2): 168-173.

Napier, K. J., Scheerer, M., \& Misra, S. (2014). Esophageal cancer: A Review of epidemiology, pathogenesis, staging workup and treatment modalities. World Journal of Gastrointestinal Oncology, 6(5), 112-120.

Newman, D. J., \& Cragg, G. M. (2016). Natural products as sources of new drugs from 1981 to 2014. Journal of Natural Products, 79(3), 629-661.

Nowak-Sliwinska, P., Weiss, A., Ding, X., Dyson, P. J., Van Den Bergh, H., Griffioen, A. W., \& Ho, C. M. (2016). Optimization of drug combinations using feedback system control. Nature Protocols, 11(2), 302-315.

Oksuz, S., Ulubelen, A., Aynechi, Y., \& Wagner, H. (1982). A guaianolide from Centaurea behen. Phytochemistry, 21(11), 2747-2749.

Pan, F., Yao, J., Chen, Y., Zhou, C., Geng, P., Mao, H., \& Fang, X. (2014). A novel long non-coding RNA FOXCUT and mRNA FOXC1 pair promote progression and predict poor prognosis in esophageal squamous cell carcinoma. International Journal of Clinical and Experimental Pathology, 7(6), 2838.

Pourhoseingholi, M. A., Vahedi, M., Baghestani, A.R. (2015). Burden of gastrointestinal cancer in Asia; an overview. Gastroenterol Hepatol Bed Bench, 8: 19-27.

Polednak, A. P. (2003). Trends in survival for both histologictypes of esophageal cancer in US surveillance, epidemiology and end results areas. International Journal of Cancer, 105: 98-100.

Qi, F., Li, A., Inagaki, Y., Gao, J., Li, J., Kokudo, N., ... \& Tang, W. (2010). Chinese herbal medicines as adjuvant treatment during chemo-or radio-therapy for cancer. Bioscience Trends, 4(6), 297-307.

Quint, L. E., Hepburn, L. M., Francis, I. R., Whyte, R. I., \& Orringer, M. B. (1995). Incidence and distribution of distant metastases from newly diagnosed esophageal carcinoma. Cancer, 76(7), 1120-1125.

Quintana, J., \& Estevez, F. (2018). Recent advances on cytotoxic sesquiterpene lactones. Current Pharmaceutical Design, 24(36), 4355-4361.

Qureshi, I., Shende, M., Luketich, J.D. (2009). Surgical palliation for Barrett's esophagus cancer. Surgical Oncology Clinics of North America, 18:547-60.

Raskin, I., Ripoll, C. (2004). Can an apple a day keep the doctor away? Current Pharmaceutical Design. 10: 3419-29.

Rates, S. M. K. (2001). Plants as source of drugs. Toxicon, 39(5), 603-613. 
Rey-Ladino, J., Ross, A. G., Cripps, A. W., McManus, D. P., Quinn, R. (2011). Natural products and the search for novel vaccine adjuvants. Vaccine. 29: 6464-6471.

Sadjadi, A., Nouraie, M., Mohagheghi, M., Mousavi-Jarrahi, A., Malekezadeh, R., Parkin, D. (2005). Cancer occurrence in Iran in 2002, an international perspective. Asian Pacific Journal of Cancer Prevention, 6:359.

Salvador, M. J., Zucchi, T. D., Schinor, E. C., Dias, D. A., Zucchi, O. L. A. D., Poli, P., \& Zucchi, T. M. A. D. (2008). Genotoxic potentials of natural products detected by a short-term test using diploid strains of Aspergillus nidulans. The Open Mycology Journal, 2(1), 48-54.

Schinor, E. C., Salvador, M. J., Ito, I. Y., De Albuquerque, S., \& Dias, D. A. (2004). Trypanocidal and antimicrobial activities of Moquinia kingii. Phytomedicine, 11(2-3), 224229.

Seca, A. M., \& Pinto, D. C. (2018). Plant secondary metabolites as anticancer agents: successes in clinical trials and therapeutic application. International Journal of Molecular Sciences, 19(1), 263.

Shakeri, A., Amini, E., Asili, J., Masullo, M., Piacente, S., \& Iranshahi, M. (2018). Screening of several biological activities induced by different sesquiterpene lactones isolated from Centaurea behen L. and Rhaponticum repens (L.) Hidalgo. Natural Product Research, 32(12), 1436-1440.

Siegel, R. L., Miller, K. D., \& Jemal, A. (2015). Cancer statistics, 2015. CA: a Cancer Journal for Clinicians, 65(1), 5-29.

Tanaka, Y. T., Tanaka, K., Kojima, H., Hamada, T., Masutani, T., Tsuboi, M., \& Akao, Y. (2013). Cynaropicrin from Cynara scolymus L. suppresses photoaging of skin by inhibiting the transcription activity of nuclear factor-kappa B. Bioorganic \& Medicinal Chemistry Letters, 23(2), 518-523.

Torre, L. A., Bray, F., Siegel, R. L., Ferlay, J., Lortet-Tieulent, J., \& Jemal, A. (2015). Global cancer statistics, 2012. CA: A Cancer Journal for Clinicians, 65(2), 87-108.

Tran, G. D., Sun, X. D., Abnet, C. C., Fan, J. H., Dawsey, S. M., Dong, Z. W., ... \& Taylor, P. R. (2005). Prospective study of risk factors for esophageal and gastric cancers in the Linxian general population trial cohort in China. International Journal of Cancer, 113(3), 456-463.

Wang, H., Deng, F., Liu, Q., \& Ma, Y. (2017). Prognostic significance of lymph node metastasis in esophageal squamous cell carcinoma. Pathology-Research and Practice, 213(7), 842-847.

Wang, J., Wu, M., Zheng, D., Zhang, H., Lv, Y., Zhang, L., .. \& Xu, H. X. (2020). Garcinol inhibits esophageal cancer metastasis by suppressing the p300 and TGF- $\beta 1$ signaling pathways. Acta Pharmacologica Sinica, 41(1), 82-92.

Weber, C., and Noels, H. (2011). Atherosclerosis: current pathogenesis and therapeutic options. Nature Medicine. 17: 1410-1422. 
Wild-Bode, C., Weller, M., Rimner, A., Dichgans, J., Wick, W. (2001). Sublethal irradiation promotes migration and invasiveness of glioma cells: implications for radiotherapy of human glioblastoma. Cancer Research. 61: 2744-50.

Wong, M. C., Hamilton, W., Whiteman, D. C., Jiang, J. Y., Qiao, Y., Fung, F. D., ... \& Yu, J. (2018). Global incidence and mortality of oesophageal cancer and their correlation with socioeconomic indicators temporal patterns and trends in 41 countries. Scientific Reports, $8(1), 1-13$.

Xavier-ravi, B., vigila Antony-varuvel, G., Thangaraj, P., Doulathabad, M. R., \& Rajan, K. (2019). Antioxidant, anti-inflammatory activities and HPLC quantification of flavonoids in Pteris tripartita Sw. a critically endangered medicinal fern from India. Biocatalysis and Agricultural Biotechnology, 21, 101304.

Yadava, R. N., \& Chakravarti, N. (2006). Novel Bioactive Triterpenoid saponin from Centanurea behen L. Journal-Institution of Chemists (India), 78(5), 135.

Yamada, K., Ishii, Y., Takeda, T., Kuroki, H., Mitoma, C., Uchi, H., ... \& Yamada, H. (2015). Effect of cynaropicrin on 2, 3, 4, 7, 8-pentachlorodibenzofuran-induced wasting syndrome and oxidative stress. Fukuoka igakuzasshi= Hukuokaactamedica, 106(5), 169-175.

Yang, G., Li, X., Wang, L., Li, J., Song, X., Chen, J., ...\& Zhou, X. (2012). Traditional Chinese medicine in cancer care: a review of case series published in the Chinese literature. Evidence-based Complementary and Alternative Medicine, 31, 751046-751054.

Yang, M. C., Choi, S. U., Choi, W. S., Kim, S. Y., \& Lee, K. R. (2008). Guaiane sesquiterpene lactones and amino acid-sesquiterpene lactone conjugates from the aerial parts of Saussurea pulchella. Journal of Natural Products, 71(4), 678-683.

Zhang, H. Z., Jin, G. F., \& Shen, H. B. (2012). Epidemiologic differences in esophageal cancer between Asian and Western populations. Chinese Journal of Cancer, 31(6), 281.

Zhang, J., Huang, F., Gong, T., \& Liu, Z. (2020). SERPINE2 promotes esophageal squamous cell carcinoma metastasis by activating BMP4. Cancer Letters, 469, 390-398.

Zhang, L., \& Hu, C. M. J. (2012). Nanoparticle-based combination therapy toward overcoming drug resistance in cancer. Biochemical Pharmacology, 83(8), 1104-1111.

Zhang, S., Won, Y. K., Ong, C. N. \& Shen, H. M. (2005). Anti-cancer potential of sesquiterpene lactones: bioactivity and molecular mechanisms. Current Medicinal ChemistryAnti-Cancer Agents, 5(3): 239-249.

Zimmermann, S., Kaiser, M., Brun, R., Hamburger, M., \& Adams, M. (2012). Cynaropicrin: the first plant natural product with in vivo activity against Trypanosoma brucei. Planta Medica, 78(06), 553-556.

Zong, Y., Yu, M., Huang, L., Chang, Y., Wang, Y., \& Che, C. T. (1994). Studies of Tibetan Medicinal Plants II. Antitumour activity of Saussureae opygmaea. International Journal of Pharmacognosy, 32(3), 284-29. 


\section{Supplementary Files}

This is a list of supplementary files associated with this preprint. Click to download.

- A.pdf

- C.pdf

- D.pdf

- Graph1.pzfx

- Graph2.pzfx

- Graph3.pzfx

- Graph4.pzfx

- Image.pdf

- S1.pdf

- S2.pdf

- S3.pdf

- S4.pdf

- S5.pdf

- S6.pdf

- comparison.pzfx 